
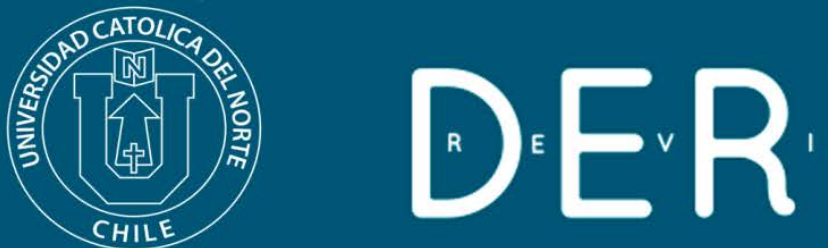

\title{
El impacto en la legislación civil chilena de la recepción de las nociones de autonomía e independencia contenidas en la Convención Interamericana de los Derechos Humanos de las Personas Mayores
}

\section{The impact on chilean civil legislation receiving the notions of au- tonomy and independence contained in the Inter-American conven- tion on the Human Rights of Elderly Persons}

\author{
Gonzalo Ruz Lártiga* (D) https://orcid.org/0000-0001-5631-471X \\ * Universidad Santo Tomás, Santiago, Chile. Profesor. Doctor en Derecho privado U. d'Aix-Marseille \\ gonzaloruz@santotomas.cl \\ (cc) BY
}

\section{Resumen:}

Se analiza el impacto que tendrá en la legislación civil-privada chilena la recepción de las nociones de autonomía e independencia que contiene la Convención Interamericana sobre la Protección de los Derechos Humanos de las Personas Mayores. Se propone, comenzar por determinar los contornos jurídicos de ambas nociones y luego, analizar el impacto que esto traerá en sede civil-privada, particularmente en el estatuto de las incapacidades y de las reglas de protección asociadas, apoyándose para ello en la experiencia comparada. Se postula que cualquier sistema que se abrace para cumplir esta tarea, deberá procurar dar la protección debida a este segmento etario sobre la base de pilares o principios fundamentales (necesidad, subsidiaridad y proporcionalidad) con pleno respeto de su dignidad como personas, sus libertades individuales y de los derechos fundamentales (autonomía e independencia) que establece la Convención.

Palabras Clave: Adulto mayor; Autonomía; Dependencia; Convención Interamericana; Guardas.

\begin{abstract}
:
The impact is analyzed of the notion of autonomy and independence contained in the Inter-American Convention on the Protection of the Human Rights of the Elderly in Chilean civil-private legislation. It is proposes to begin by deter-mining the legal contours of both notions and then analyzing the impact that this will bring in civil-private, particularly in the status of disabilities and associated protection rules, based on comparative experience. It is postulated that any system that is embraced to fulfill this task, should seek to give due protection to this age segment on the basis of pillars or fundamental principles (necessity, subsidiarity and proportionality) with full respect for their dignity as individuals, their individual freedoms And of the fundamental rights (autonomy and independence) established by the Convention.
\end{abstract}

Keywords: Elderly; Autonomy; Dependence; Inter-American Convention; Guards. 
El impacto en la legislación civil chilena de la recepción de las nociones de autonomía e independencia contenidas en la Convención Interamericana de los Derechos Humanos de las Personas Mayores

\section{Introducción}

Escribía Víctor Hugo (1865) que "la miseria de un niño interesa a una madre, la miseria de un hombre joven interesa a una joven, la miseria de un viejo no interesa a nadie. De todas las miserias esta es la más fría" (p. 573). Una constatación cruda de finales del siglo XIX sobre el abandono de los adultos mayores que ha permanecido en el tiempo, pero que parece estar cambiando o, al menos, en esa dirección es que el Consejo Permanente de la Asamblea General de la OEA, en sesión celebrada el 9 de junio de 2015, aprobó la Convención Interamericana sobre la Protección de los Derechos Humanos de las Personas Mayores, en adelante "la Convención", que consta de siete capítulos en que se distribuyen los 41 artículos del texto. Chile, firmante del Acuerdo ${ }^{1}$ tendrá un nuevo marco de reconocimiento de derechos fundamentales para este segmento etario que le impondrá una serie de obligaciones las que producirán la necesidad de adecuar la legislación interna a esta Convención, que pasará, desde su entrada en vigencia, a constituir derecho vigente y aplicable en Chile².

En el Capítulo IV, "Derechos protegidos", se contiene un artículo $7^{\circ}$ titulado "Derecho a la independencia y autonomía" que impone a los Estados partes un reconocimiento de estas condiciones (autonomía e independencia) en los adultos mayores elevándolas a derechos fundamentales. Ambas nociones, además, se integran en el artículo $3^{\circ}$, en su letra c) como principios generales aplicables a la Convención ${ }^{3}$.

Las nociones de autonomía e independencia, han sido objeto, en general, de variados y multidisciplinarios estudios y aparece de ellos una constante que se repite en tres aspectos: $1^{\circ}$. Ambas nociones son polisémicas, multidisciplinares y pluricausales, es decir, nociones a geometría variable que hace muy difícil su conceptualización integral; $2^{\circ}$. Lo que mejor caracteriza estas nociones es su dinámica relacional, es decir, aisladamente, en apariencia, están llenas de contenido, pero que, en realidad no se revelan en toda su extensión, sino cuando se asocian entre sí o unas y otras con

\footnotetext{
${ }^{1}$ A la fecha de presentación de este trabajo se había aprobado en la Cámara de Diputados y el Senado, esperándose que el Gobierno depositara el instrumento en la OEA.

${ }^{2}$ La Convención entraba en vigor (Organización de Estados Americanos [OEA], 2015, art. 37, inc. 3) al trigésimo día a partir de la fecha en que se haya depositado el segundo instrumento de ratificación o adhesión de la Convención en la Secretaría General de la OEA. Desde que opere la ratificación interna de cada Estado, la Convención entrará en vigor el trigésimo día a partir de la fecha en que tal Estado haya depositado el instrumento correspondiente (inciso $4^{\circ}$ ).

${ }^{3}$ La noción de autonomía, en su dimensión jurídica y como principio fundamental de la persona humana, aparecería, en Europa a partir del caso Pretty (Pretty c. Royaume-Uni, 2002), asociado a la noción de autodeterminación. En efecto, la Corte precisa que "aunque no se encuentre establecido en ningún caso anterior que el artículo $8^{\circ}$ de la Convención implica un derecho a la autodeterminación propiamente tal, la Corte considera que la noción de autonomía personal refleja un principio importante que debe guiar la interpretación de las garantías del artículo $8^{\circ}$." La CEDH reconoce la existencia de un nuevo principio y, hasta ese momento, exclusivamente europeo, que la Sra. Pretty llama autodeterminación pero que la Corte prefiere denominar de autonomía personal. D'Alton (2009).
} 
elementos propios de cada disciplina en la que son aplicables. En Derecho, las nociones de autonomía e independencia son también inseparables de otras (v.gr. voluntad, capacidad y libertad) e influyen directamente en la configuración de la noción de dignidad de la persona ${ }^{4}$, en particular tratándose de personas adultas vulnerables en razón de su edad; $3^{\circ}$. Ambas nociones, en su faz negativa, son manifestaciones de un común denominador: una especial vulnerabilidad que puede afectar a estas personas ${ }^{5}$.

Se postula en este trabajo que la determinación de un perímetro que fije contornos más o menos precisos de ambas nociones, facilitará la tarea de recepcionar estos derechos fundamentales consagrados en la Convención. Demostrado lo anterior, se postula que el impacto de su introducción traerá consigo la necesidad de efectuar serias reformas en sede civil-privada al estatuto de las incapacidades y de las reglas de protección asociadas. Se concluye, sobre la base de algunos ejemplos de legislación comparada, que cualquier sistema que se abrace, deberá procurar dar la protección debida a este segmento etario sobre la base de pilares o principios fundamentales (necesidad, subsidiaridad y proporcionalidad) con pleno respeto de su dignidad como personas, sus libertades individuales y de estos derechos fundamentales (autonomía e independencia) que establece la Convención.

\section{Hacia la definición de los contornos jurídicos de la noción de au- tonomía y dependencia del adulto mayor}

Ha quedado dicho que las nociones de autonomía e independencia son nociones a geometría variable, es decir, nociones que se caracterizan por sus múltiples formas (polisémicas), un tratamiento distinto y por un conjunto variado de disciplinas (multidisciplinares) y la integración no de una sino de muchas causas (pluricausales), que sirven para explicarlas y construirlas. Pretender ofrecer intentos de conceptualización desde varias disciplinas se apartaría y excedería con creces los propósitos de este trabajo. Se partirá, entonces, de una percepción jurídica básica de ambas nociones y cómo el Derecho ha caracterizado cada una de ellas, confiriéndoles así un perímetro más definido y contornos más o menos precisos para la disciplina, lo que permitirá integrarlas mejor.

\footnotetext{
${ }^{4}$ Dorn Garrido (2011); Sledziewski (2011); Lathrop (2009).

${ }^{5}$ Sobre la compleja noción de vulnerabilidad y su recepción por el Derecho: Dutheil-Warolin (2004); Favier (2012); Fietcher-Boulvard (2000); Goldfarb (2016); Hauser (2011); Lacour (2007, 2009); Mislawski, Roger (2000).
} 
El impacto en la legislación civil chilena de la recepción de las nociones de autonomía e independencia contenidas en la Convención Interamericana de los Derechos Humanos de las Personas Mayores

\subsection{La caracterización jurídica de las nociones de autonomía y depen- dencia: la autonomía decisional y la dependencia funcional ${ }^{6}$}

La noción de autonomía, tomada en forma aislada, es inasible y carece de sentido preciso para el Derecho, es decir, puede significar todo y muchas cosas a la vez. A pesar de ello, en términos jurídicos, aún en los más amplios, la noción puede comenzar a delimitarse. En una primera y general acepción jurídica, la autonomía de la persona puede definirse como el poder de determinarse a sí misma, la facultad de darse su propia ley: así, la persona es autónoma cuando se gobierna a sí misma, por sí misma. La noción de autonomía personal ${ }^{8}$ va asociada, entonces, y particularmente en sede civil patrimonial, con una trilogía de constructos jurídicos ya existentes (voluntad, libertad y capacidad) o, más precisamente, las supone. En efecto, supone la voluntad, como aptitud de juzgar, es decir, como esa facultad de prever y de elegir lo que se quiere (de ahí, por ejemplo, la construcción autonomía de la voluntad). Sin esa "coordinación jerárquica de nuestros deseos", la persona carece de autonomía decisional. Supone también la libertad de decidir y de actuar, sea aceptando o rechazando, en función de esa elección, las diferentes alternativas que se le presentan (de ahí, también, por ejemplo, el corolario de la construcción anterior: la libertad contractual). La libertad de tomar decisiones se dará sí y sólo sí el individuo dispone de voluntad para elegir lo que quiere. En fin, la capacidad, noción evolutiva, permite mostrar que, así como la persona va adquiriendo progresivamente la facultad de poder

\footnotetext{
${ }^{6}$ Gzil emplea la expresión autonomía funcional, caracterizándola en dos tipos: autonomía funcional física, referida a la capacidad de la persona para efectuar por sí misma un determinado número de actos de la vida cotidiana; y la autonomía funcional psíquica, referida a la capacidad de la persona de determinarse por sí misma con conocimiento de causa. Gzil (2009) La primera categoría, en Derecho, se ha tendido a asociar a la noción de dependencia; mientras que la segunda, a la noción de autonomía decisional. Ver también: Gzil, Rigaud y Lacour (2008). La noción de autonomía decisional también es propia de la disciplina de la ética médica principialista, a partir de la publicación de los Principles of Biomedicals Ethics de Tom Beauchamp y James Childess en 1979. Schumacher y Meyer (2015).

${ }^{7}$ Cornu (2005, p. 93). Etimológicamente, autonomía proviene del griego Aủtovouía: autos, por sí mismo, y nomos: ley.

${ }^{8}$ La expresión "autonomía personal" sería una traducción de la expresión inglesa "Independent living", movimiento que se inicia en los Estados Unidos de Norteamérica a fines de la década de los 60 . Ver DeJong (1979). Este movimiento tuvo como centro de atención principalmente a personas afectadas por grandes deficiencias físicas constatando y denunciando la práctica de derivación a centros de larga estadía de afectados por deficiencias graves, que producía un bloqueo de sus vidas y de sus personalidades. En ese contexto y frente a esta situación de supeditación de la voluntad, reivindican la vida autónoma, en el doble plano de la capacidad personal de elegir y de llevar a cabo las elecciones. Luego la expresión "autonomía personal" habría sido empleada en España por Puig de la Bellacasa (1990) en un artículo sobre discapacidad, donde el autor proponía tres modelos en la evolución de las mentalidades sociales, uno de ellos era el "Paradigma de la autonomía personal: con el logro de una vida independiente como objetivo básico". En fin, el concepto de autonomía personal ha sido consagrado sólo recientemente en el orden jurídico europeo, en donde ha sido definido por vía pretoriana como la facultad para una persona humana de llevar su vida como ella lo desee. Ver Hurpy (2015); Levinet (2009).

${ }^{9}$ Avelino León (1963, p. 45), citando a Manuel Somarriva, se la atribuye a René Demogue, en circunstancias que la frase ("...cette coordination hiérarchique d'éléments divers est la raison d'être de la force juridique de la volonté ») la construye Demogue (1911, p, 287) a partir de la obra de Ribot (1888, p.149).
} 
obligarse por sí misma, sin el ministerio ni la autorización de otro (de ahí la construcción conocida como capacidad legal ${ }^{10} \mathrm{o}$ de ejercicio), es predecible que en algún momento este summum o plenitud de capacidad progresivamente irá también afectándose o perdiéndose.

Por ello, el adulto -en nomenclatura del codificador civil- (el que ha alcanzado 18 años de edad), se caracteriza por su plena autonomía, la que se manifiesta en libertad de iniciativa y de decisión sobre sus propios intereses y la facultad de obrar por sí mismo sin el ministerio ni la autorización de otro. La autonomía de la persona, en esta primera acepción y que será nuestro punto de partida, se erige, entonces, como noción en absoluta relación con la voluntad, capacidad y libertad del individuo, las que, en conjunto, justificarán que sobre sí recaiga el peso de asumir la responsabilidad civil de las consecuencias de sus actos.

Este estado de autonomía en el adulto no está limitado por la ley en razón de la edad. Ésta presume que todo adulto es plenamente capaz. Sin embargo, y he aquí la raíz del asunto, la edad puede constituirse en un factor que haga vulnerable al adulto en razón de la pérdida de autonomía funcional física y psíquica que puede afectarle mientras más envejece. En concreto, el adulto no se ve limitado en su autonomía (voluntad, capacidad y libertad), sino cuando el envejecimiento va acompañado de un cierto grado de fragilidad o de una especial vulnerabilidad, que puede exponerlo a abusos e incluso tornarlo inapto para tomar decisiones personales o patrimoniales. Más claro todavía, para el Derecho es en la pérdida progresiva de autonomía decisional -en razón de la avanzada edad- donde se encuentra una de las causas que vuelve a la persona especialmente frágil o vulnerable al punto de afectar el cabal ejercicio de sus derechos y colocarlo en una posición jurídica desventajosa.

De ahí entonces que, tal como ya lo han comprendido legislaciones comparadas, los distintos grados de vulnerabilidad debieran provocar distintas medidas de protección del ordenamiento jurídico ${ }^{11}$. El adulto mayor vulnerable, en razón de su progresiva pérdida de autonomía decisional, debiese ocupar un lugar dentro de las categorías de personas que el Derecho civil protege pues, aunque no está desprovisto de voluntad, capacidad o libertad, en síntesis, de autonomía, ella está debilitada o se ha perdido progresivamente, lo que la vuelve especialmente vulnerable. Así como el adulto se caracteriza por su autonomía decisional, el adulto mayor, vulnerable en

\footnotetext{
${ }^{10}$ Art. 1445 inciso final del Código civil: "La capacidad legal de una persona consiste en poderse obligar por símisma, y sin el ministerio o la autorización de otra."

${ }^{11}$ Un ejemplo claro es la regla que se contiene en el Art. 415 del Código civil francés, según el cual: "(Inc. $\left.1^{\circ}\right)$ Los mayores reciben la protección de su persona y bienes que su estado o situación hagan necesaria según las modalidades previstas en este título. (Inc. $2^{\circ}$ ) Esta protección se establece y asegura en el respeto de las libertades individuales, de los derechos fundamentales y de la dignidad de la persona. (Inc. $3^{\circ}$ ) Esta protección tiene por finalidad el interés de la persona vulnerable. Ella favorece en la medida de los posible, su autonomía. (Inc. $4^{\circ}$ ) Ella constituye un deber de las familias y de la comunidad."
} 
El impacto en la legislación civil chilena de la recepción de las nociones de autonomía e independencia contenidas en la Convención Interamericana de los Derechos Humanos de las Personas Mayores

razón de su avanzada edad, se caracteriza por presentar pérdida de autonomía decisional, la que puede definirse como la imposibilidad de la persona de elegir y expresar una preferencia, de determinarse por sí misma con conocimiento de causa.

La noción de dependencia, al igual que la de autonomía, ha sido objeto de estudio desde variadas disciplinas, aunque gran número de ellas y así parece asirla el Derecho también, la representan como una manifestación negativa de la autonomía funcional física, siguiendo la nomenclatura de Gzil $\left(2008\right.$, p.163) ${ }^{12}$. Habría dependencia cuando se presente un estado avanzado de limitaciones físicas funcionales, generalmente irreversibles, lo que se traduce en "la imposibilidad de realizar una o muchas actividades de la vida cotidiana sin la ayuda de otro" ${ }^{\prime 3}$.

El grado de dependencia en el adulto mayor, dependerá del nivel de limitaciones funcionales y de restricciones que le afectan para realizar las actividades cotidianas y no directamente o necesariamente de su edad o de su estado de salud. Sin embargo, la frontera entre dependencia, vejez y problemas de salud es bien débil dado que esas limitaciones funcionales resultan, a menudo, de problemas actuales o pasados de salud y aumenta, generalmente, cuanto más avanzada es la edad del individuo. Los distintos grados de dependencia (leve o moderada, severa y gran dependencia ${ }^{14}$ ) definirán el grado de apoyo que necesite la persona, desde una simple y puntual asistencia para una o más actividades cotidianas hasta aquellas en que se necesita la presencia permanente de un cuidador.

En teoría, entonces, toda persona capaz debe ser tratada como un agente autónomo e independiente que puede protegerse a sí mismo y dar protección a los suyos, pero -en la práctica- no es menos cierto que las personas que en razón de su

\footnotetext{
${ }^{12}$ Según el Estudio Nacional de Dependencia en las Personas Mayores, (González et al., s.f.) "las definiciones más utilizadas de dependencia se enmarcan dentro de las limitaciones o incapacidad para efectuar las actividades de la vida diaria. Es así como Barthel la describe como la 'incapacidad funcional en relación con las actividades de la vida diaria'. Baltes y Wahl la definen como 'la necesidad de ser ayudado para ajustarse a su medio e interactuar con él'. En la misma línea, la Asociación Americana de Retraso Mental, la define como 'la necesidad de apoyos que precisa un individuo en el desenvolvimiento corriente en las diversas áreas de habilidades adaptativas'. Por su parte, Abanto, desde un punto de vista asistencial, enfatiza la necesidad de ayuda: 'cuando se recurre a un tercero o cuidador y estos cuidados afectan los actos elementales de la vida diaria'." (p. 11). Sobre el tratamiento de la noción de dependencia en la vejez ver La protección internacional de las personas dependientes (2014); García Martínez; Ennuyer (2003).

${ }^{13}$ Tomado de Wolff, Boult, Boyd y Anderson (2005).

${ }^{14}$ Esta clasificación no es universal, aunque sigue los parámetros de la Clasificación Internacional del Funcionamiento, de la Discapacidad y de la Salud, (CIF) del 2001 de la OMS. Estas categorías se obtienen a partir de la aplicación de uno o más de los principales métodos internacionales para realizar una valoración del estado funcional en adultos mayores con dependencia: Índice de Katz para determinar el nivel de dependencia; Medida de Independencia Funcional (FIM) para la funcionalidad y nivel de asistencia dada por el cuidador; Índice de Barthel para valorar la independencia respecto a las AVD; el Minimental abreviado (MMSE) para determinar el estado cognitivo y la Escala de Zarit que evalúa la sobrecarga de los cuidadores. Trigás-Ferrín, Ferreira-González y Meijide-Míguez (2011).
} 
edad se tornan vulnerables, requieren de protección jurídica, aunque no de manera de hacerlas perder su autonomía e independencia ${ }^{15}$.

Un estatuto protector en sede civil-privada del adulto mayor en razón de su vulnerabilidad asociada a los factores mencionados se hace necesario y la entrada en vigencia de la Convención es una oportunidad importante para su futuro diseño.

\subsection{La elección tomada por la Convención en la recepción de las nociones de autonomía y dependencia del adulto mayor}

Al agrupar la noción de autonomía con la noción de independencia, la Convención hace una elección determinante para el intérprete en la búsqueda de delimitar sus contornos ${ }^{16}$. En efecto, la Convención parece limitar, en el inciso primero de su artículo $7^{\circ}$, la noción de autonomía del adulto mayor a su dimensión funcional psíquica (autonomía decisional) ${ }^{17}$; mientras que la noción de independencia la tomaría en sentido negativo (dependencia), en una dimensión funcional física. Lo anterior queda de manifiesto en la letra a) del inciso segundo del mismo artículo $7^{\circ}$ que dispone que los Estados, asegurarán, en especial: “a) El respeto a la autonomía de la persona mayor en la toma de sus decisiones, así como a su independencia en la realización de sus actos"18. Al titular el artículo $7^{\circ}$, "Derecho a la independencia y autonomía", se pone en evidencia que para la Convención ambas nociones, en el mayor adulto vulnerable, son diferentes, aunque no antagónicas u opuestas, sino complementarias.

\footnotetext{
${ }^{15}$ Desvaux-Bernheim, S. (2010)

${ }^{16} \mathrm{El} \mathrm{Art.} 1^{\circ}$, inciso $2^{\circ}$ de la Convención deja claramente establecido el compromiso del Estado parte de la Convención: "Si el ejercicio de los derechos y libertades mencionados en esta Convención no estuviere ya garantizado por disposiciones legislativas o de otro carácter, los Estados Parte se comprometen a adoptar, con arreglo a sus procedimientos constitucionales y a las disposiciones de esta Convención, las medidas legislativas o de otro carácter que fueren necesarias para hacer efectivos tales derechos y libertades."

${ }^{17}$ En efecto, dispone el inciso primero del referido artículo $7^{\circ}$ que: "Los Estados Parte en la presente Convención reconocen el derecho de la persona mayor a tomar decisiones, a la definición de su plan de vida, a desarrollar una vida autónoma e independiente, conforme a sus tradiciones y creencias, en igualdad de condiciones y a disponer de mecanismos para poder ejercer sus derechos."

${ }^{18} \mathrm{Art.} 7^{\circ}$ inciso $2^{\circ}$ : "Los Estados Parte adoptarán programas, políticas o acciones para facilitar y promover el pleno goce de estos derechos por la persona mayor, propiciando su autorealización, el fortalecimiento de todas las familias, de sus lazos familiares y sociales, y de sus relaciones afectivas. En especial, asegurarán:

a) El respeto a la autonomía de la persona mayor en la toma de sus decisiones, así como a su independencia en la realización de sus actos.

b) Que la persona mayor tenga la oportunidad de elegir su lugar de residencia y dónde y con quién vivir, en igualdad de condiciones con las demás, y no se vea obligada a vivir con arreglo a un sistema de vida específico.

c) Que la persona mayor tenga acceso progresivamente a una variedad de servicios de asistencia domiciliaria, residencial y otros servicios de apoyo de la comunidad, incluida la asistencia personal que sea necesaria para facilitar su existencia y su inclusión en la comunidad, y para evitar su aislamiento o separación de ésta."
} 
El impacto en la legislación civil chilena de la recepción de las nociones de autonomía e independencia contenidas en la Convención Interamericana de los Derechos Humanos de las Personas Mayores

La Convención recepciona, en síntesis, una noción de autonomía ya caracterizada como autonomía decisional que, en el contexto estrictamente jurídico, como ya se dijo, posee contornos bastante más precisos. En especial, en sede civil-patrimonial, la autonomía decisional nos acerca a la noción de capacidad legal o de ejercicio como una expresión de la voluntad generadora de actos jurídicos válidos. Un gran avance puede, entonces, visualizarse en aras a la definición de los contornos jurídicos de la noción de autonomía que la Convención consagra como derecho fundamental del adulto mayor. Al menos en un escenario ya conocido es que deberá modernizarse nuestra legislación civil privada.

Otra situación se presenta con la noción de dependencia, también recepcionada por la Convención ya caracterizada, en su dimensión funcional física, donde aparece relacionada a la necesidad de intervención de un tercero para actuar en el ámbito de las actividades físicas de la vida diaria del adulto mayor ${ }^{19}$.

A diferencia de la noción de autonomía decisional, la de dependencia, en sede civil-privada, no es homologable en nuestra legislación. Por el contrario, cuando el Código civil emplea la palabra "(in)dependencia" lo hace en referencia a la autonomía decisional de la persona, como cuando la utiliza en el inciso primero de los Arts. 159 y 173 del Código civil, en materia de separación de bienes ${ }^{20}$ o en el Art. 2020, inciso $3^{\circ}$, en materia de responsabilidad civil por el hecho ajeno ${ }^{21}$. Lo anterior es, sin embargo, justificable, si se piensa que en Francia, por ejemplo, la noción de mayores adultos dependientes (personnes âgées dépendantes) aparece recién en 1997 en una ley asistencial ${ }^{22}$ y en España, en el campo de la asistencia sanitaria ${ }^{23}$.

\footnotetext{
${ }^{19}$ Esta variación y precisión, al mismo tiempo, de la noción de dependencia, ya había sido abordada por el Consejo de Europa en la Recomendación № 98 (9) relativa a la dependencia, de 18 de septiembre de 1998, en donde se la calificaba como "un estado en el que se encuentran las personas que por razones ligadas a la falta o la pérdida de autonomía física, psíquica o intelectual, tienen necesidad de asistencia y/o ayudas importantes a fin de realizar los actos corrientes de la vida diaria y, de modo particular, los referentes al cuidado personal." Noción que evolucionaría, como se señala en La protección internacional de las personas dependientes (2014). "Cinco años más tarde, [cuando] un informe elaborado por un Grupo de expertos del Consejo de Europa, define la dependencia como "un estado en que las personas, debido a la falta o la pérdida de autonomía física, psicológica o mental, necesitan de algún tipo de ayuda y asistencia para desarrollar sus actividades diarias. La dependencia podría también estar originada o verse agravada por la ausencia de integración social, relaciones solidarias, entornos accesibles y recursos adecuados para la vida de las personas mayores". Roman (2008).

${ }^{20}$ Art. 159, inciso $1^{\circ}$, del Código civil. "Los cónyuges separados de bienes administran, con plena independencia el uno del otro, los bienes que tenían antes del matrimonio y los que adquieren durante éste, a cualquier título."; Art. 173, inciso $1^{\circ}$, del Código civil. "Los cónyuges separados judicialmente administran sus bienes con plena independencia uno del otro, en los términos del artículo 159."

${ }^{21}$ Art. 2020, inciso $3^{\circ}$, del Código civil. "Así el tutor o curador es responsable de la conducta del pupilo que vive bajo su dependencia y cuidado".

${ }^{22}$ Ley $\mathrm{N}^{\circ}$ 97.60. de 24 de enero de 1997, que establecerá la denominada PSD o Prestation Spécifique Dépendance. Antes, los adultos mayores (sobre 60 años) eran considerados por la una Ley de 30 de junio de 1975, de orientación a favor de personas discapacitadas, beneficiarias de ACTP o Allocation Compensatrice de Tierce Personne, lo que en los hechos significaba crear una sub-categoría de personas discapacitadas sólo en razón de la edad. El profesor Ennuyer (2003, p.96) crítica esta subcategorización preguntándose: “¿Cómo explicar esta distinción, que se establece en el curso de los años, entre inca-
} 
La tendencia actual, empero, es a insertar la noción de dependencia, en sede civil, en una dinámica relacional con la de autonomía, consciente que, a mayor dependencia funcional más se limita el ejercicio de la autonomía decisional del mayor adulto. Ambas nociones se encuentran a la base de los desarrollos del Derecho contemporáneo de la protección jurídico-privada del mayor adulto atendida la especial situación de vulnerabilidad de este sector etario.

En principio, concluyamos, que a diferencia de los que han perdido o no han adquirido plena autonomía decisional (incapaces absolutos o relativos en la nomenclatura de nuestro Código civil), los que requieren del ministerio o la autorización de otro para poder actuar en el mundo del Derecho, el adulto mayor requiere, en cambio, asistencia y protección especial del ordenamiento jurídico pues, aunque capaz, es especialmente vulnerable en razón del grado de pérdida de autonomía decisional o del incremento de su dependencia funcional física que le afecta como consecuencia de su edad avanzada y otros fenómenos asociados.

\section{El impacto de la recepción de la noción de autonomía e indepen- dencia del adulto mayor en la legislación civil chilena}

La Convención exigirá al Estado de Chile medidas de adaptación de sus políticas públicas, mecanismos de apoyo y de su institucionalidad vigente, amén de cambios internos en la legislación civil-privada que le aseguren al mayor adulto la protección debida con pleno respeto de sus libertades individuales, de sus derechos fundamentales (entre ellos a su autonomía e independencia), y de su dignidad como personas, lo que impactará claramente en las reglas actuales de la capacidad civil, contenidas en el Código del ramo. Tarea nada fácil pues la ecuación es tremendamente compleja tratándose, en especial, de adultos mayores ${ }^{24}$ : en la búsqueda de reconocerles y otorgarles mayor autonomía e independencia se corre el riesgo de

pacidad y dependencia, distinción que se ha transformado en una segregación entre 'personas discapacitadas' y 'adultos mayores dependientes'?".

${ }^{23}$ Ley 41/2002, de 14 de noviembre, básica reguladora de la autonomía del paciente y de derechos y obligaciones en materia de información y documentación clínica. Posteriormente, la aprobación de la Ley 39/2006 constituye un avance importante en el panorama nacional de los servicios sociales al considerar la promoción de la autonomía y la atención a las situaciones de dependencia como derecho de la persona, es decir, como un derecho subjetivo para la ciudadanía.

${ }^{24}$ Lavaud-Legendre (2010), sostiene que el Estado francés respondería a los estados de vulnerabilidad de las personas con una multiplicación de técnicas que buscarían la protección de la persona por sí misma, a fin de favorecer su autonomía e independencia, lo que pone en duda desde que estas medidas de protección no se acompañan, frecuentemente, de los soportes necesarios para lograr esta autonomía. Sobre este punto, y la pugna de modelos de protección, recomendamos la lectura de Ehrenberg (2010), y la crítica de Castel (2010). El estudio se puede completar con la respuesta de Ehrenberg (2010b) a la crítica de Castel. 
El impacto en la legislación civil chilena de la recepción de las nociones de autonomía e independencia contenidas en la Convención Interamericana de los Derechos Humanos de las Personas Mayores

desprotegerlos; y en la búsqueda de concederles mayor protección se corre el riesgo de privarlos de autonomía e independencia. La búsqueda del justo equilibrio entre autonomía e independencia, por un lado; y de protección jurídico-privada, por el otro, es y debe ser el resultado de una óptima legislación.

\subsection{Un impacto profundo en las reglas de la capacidad civil: ¿Hacia la su- peración de la summa divisio entre personas capaces e incapaces?}

En principio, el Código civil chileno considera sujetos protegibles a aquellas personas que no pueden dirigirse a sí mismos o administrar competentemente sus negocios, excluidos los que se encuentran sujetos a patria potestad, pues en ese caso su padre o madre podrán prestarle la protección debida ${ }^{25}$. Sin embargo, esta aseveración no es ni exacta ni deseable. No es exacta, pues no todas ellas reciben la protección del ordenamiento jurídico. Para recibir esa protección la persona debe integrar el catálogo (numerus clausus) de incapaces del Art. 1447 del Código civil. No es tampoco deseable, desde que la protección que entrega el ordenamiento jurídico es la incapacitación civil, que coloca a un tercero en lugar de la persona protegida para expresar su voluntad o para autorizarla en la ejecución o celebración de todos o un gran número de actos jurídicos. En la primera hipótesis (incapacitación absoluta), la protección niega toda autonomía decisional a la persona protegida, sin reconocerle, en principio, zonas o ámbitos preservados o una esfera de autonomía para consentir libremente por sí misma en la realización de actos estrictamente personales ${ }^{26}$, zonas

\footnotetext{
${ }^{25}$ Artículo 338 del Código civil chileno.

${ }^{26}$ Es lo que recoge el Derecho francés con la noción d'acte personnel de la personne vulnérable, que fue expresamente introducido por el Art. 458 del Code civil, nacido de la Ley de 5 de marzo de 2007, que crea una categoría de actos que dado su carácter estrictamente personal, requieren necesariamente el consentimiento del mayor protegido, no pudiendo ser ni autorizado ni representado por su curador. Con ello se reconoce la noción de capacidad natural de la persona. El inciso $2^{\circ}$ de esta disposición presume que son tales la declaración de nacimiento de un hijo (a), su reconocimiento, los actos de autoridad parental relativos a la persona del hijo (a), la declaración de la elección o del cambio de nombre de un hijo (a) y el consentimiento necesario para su propia adopción o la de sus hijos (as). Mallet (2016), advierte que la coordinación de los actos de esta naturaleza que se numeran con otras disposiciones del mismo Código (sobre todo con aquella que se contienen en el Art. 459, inciso $1^{\circ}$, denominados "decisiones relativas 'a su persona'", que si permiten asistencia o representación), será muy delicada. Ver también: Maria (2016, p. 36) que comenta un fallo muy interesante de 2015, en materia de matrimonio de un mayor protegido (Audience publique, du mercredi 2 décembre 2015), en el que se desestima la solicitud del tutor del mayor que pedía la autorización del juez para el matrimonio de éste, dispone que se trataba de un acto estrictamente personal que no admitía autorización ni representación. En la misma línea, Moracchini-Zeidenberg (2012), pone de relieve, con la modificación de 2007 del Código civil, la consagración de la teoría de la capacidad natural, según la cual ciertos actos no pueden dar lugar a representación ni tampoco a autorización por estar íntimamente ligados a la persona de su autor. Expresa que esta juridización de la capacidad natural hace que debamos interrogarnos sobre las consecuencias de la incapacidad natural para ejecutar ciertos actos, a fin de proponer alternativas a las incapacidades de goce que contiene el Derecho positivo. Más crítica es Salvage-Gerest (2009), que sobre la numeración no exhaustiva que contiene el Art. 458 del Code concluye que la protección real de las personas bajo guarda más vulnerables se sacrifica en favor de una autonomía idealizada y peor aún advierte que es la protección de los hijos de estas personas la que
} 
o ámbitos que se justifican a partir del reconocimiento de la existencia de una capacidad natural ${ }^{27}$, de base o usual de toda persona, inclusas las incapaces. En la segunda hipótesis (incapacitación relativa), se reconoce un grado de autonomía sujeta, empero, a control, desde que la decisión debe ser refrendada por el tercero que la protege para que pueda producir efectos jurídicos.

Las hipótesis de personas que habiendo alcanzado plena capacidad, autonomía decisional e independencia funcional, pero que sin embargo en razón de su avanzada edad han ido perdiendo éstas progresivamente tornándose especialmente vulnerables, no fue considerada finalmente por nuestro decimonónico legislador, como protegibles ${ }^{28}$. La tendencia de la época ${ }^{29}$, y así lo demostraba el principal modelo de codificación, el Code civil de Napoleón de 1804, se limitaba sólo a distinguir entre personas capaces o incapaces de obrar o actuar. El gran aporte de nuestro legislador fue el de tipificar las categorías de incapaces (absolutos y relativos) asignándoles efectos jurídicos precisos a sus actos ${ }^{30}$.

Según Barrientos Grandón (2016, Vol. 2, p. 335), Bello siguió el derecho español vigente en Chile antes de la codificación, lo que se demuestra en las indicaciones que habría hecho en el primer Proyecto del Libro "De los contratos y obligaciones convencionales" sobre las fuentes empleadas en la redacción del actual Art. 1447 del

más se afecta, pues todos los actos del listado legal, salvo uno, conciernen el estado civil y la educación de éstos. Para un excelente resumen veáse Hauser (2012);

${ }^{27}$ La expresión "capacidad natural" no la tomamos en el sentido que tradicionalmente se le ha dado a la capacidad de goce desde De Savigny (1855), sino como un conjunto de actos que dada su naturaleza personal están excluidos de representación o autorización de un tercero. Citando al profesor Ramos Chaparro que expresa que "la capacidad natural impregna o permea todo el ordenamiento de forma ubicua y difusa", agregando que "los derechos contemporáneos codificados han recogido en fórmulas más o menos sintéticas y estereotipadas (v.gr., autogobierno, libre determinación de la voluntad, cabal juicio, etc.) este dato del funcionamiento psíquico adecuado del sujeto en toda actuación jurídica en que estén implicados sus intereses", la profesora Brandi Taiana (2004) configura la noción señalando que "entre la capacidad jurídica y la capacidad de obrar, aún con graduaciones, a la que habitualmente se hace referencia, hay algo más a tener en cuenta. Existe esa capacidad que tiene que ver con el 'entender y querer' y la 'lucidez actual' más allá de las situaciones subjetivas concretas de cada caso."(p. 8)

${ }^{28}$ En cursivas la palabra "finalmente" pues, originalmente Bello había consignado una curaduría para "los que por enfermedad permanente no pueden emplear en la administración de sus bienes suficiente cuidado y dilijencia". Véase. Barrientos Grandón, Javier (2016, Vol. 1, p. 626) .

${ }^{29}$ La distinción entre personas capaces e incapaces se contenía en el Art. 1123 del Código civil francés; Art. 1186 del Código Napolitano, Art. 1210 del Código Sardo, Art. 823 de Código del Cantón de Vaud; Art. 1365 del Código Holandés; Art. 1775 del Código de la Luisiana, Art. 865 del Código civil general del Imperio Austriaco, Art. 986 del Proyecto de García Goyena, entre otros, que sirvieron por lo demás de influencia en materia de condiciones para la formación de los contratos y de las obligaciones para el codificador nacional.

${ }^{30}$ Advertimos que Bello no hizo comentario alguno en el Mensaje acerca de esta división entre incapacidades absolutas, relativas y particulares. En materia de guardas sólo se trató de un simple reordenamiento y simplificación de reglas ya aplicables en Chile en ese momento. Es lacónica su explicación en el Mensaje: "se han definido con precisión las diferentes especies de guardas; las causas que inhabilitan o excusan de ejercer estos cargos, sus facultades administrativas, sus deberes, sus emolumentos, sus responsabilidades." 
El impacto en la legislación civil chilena de la recepción de las nociones de autonomía e independencia contenidas en la Convención Interamericana de los Derechos Humanos de las Personas Mayores

Código civil" ${ }^{31}$. En nuestra opinión, el codificador chileno siguió la tendencia de la época (mantener la summa divisio entre capaces e incapaces de obrar), aunque innovó al establecer en una única disposición (Art. 1447) una gradación de las incapacidades de ejercicio, categorizándolas en absolutas y relativas, disponiendo que los actos realizados por los primeros no producían ni aun obligaciones naturales y no admitían caución, mientras que para los segundos, podían tener valor en ciertas circunstancias y bajo ciertos respectos, determinados por las leyes. Del mismo modo, en sede de protección de incapaces, esa summa divisio llevaría a otra. La distinción de incapaces absolutos y relativos se trasladaría a la forma de actuar en la vida: representación para los incapaces absolutos, y ésta o autorización para los relativos.

Esta división, asociada a las formas clásicas de protección para los incapaces (tutelas y curatelas), se mantendrá anclada en las legislaciones continentales europeas hasta bien pasada la mitad del siglo $X X^{32}$. A partir de ahí, un fuerte movimiento de reforma parece indicar que la modernización de la protección de los mayores vul-

\footnotetext{
${ }^{31}$ Las fuentes indicadas por el mencionado profesor, corresponderían a tres Leyes del Código de las Siete Partidas (Leyes 4 y 5, T. 11, Part. V y Ley 2, T. 7, Part. 1) y una de la Novísima Recopilación de Leyes de España de 1805 (Ley 11, T. 1, L. 10 nov. R.). Según Casso y Romero y Cervera y Jiménez-Alfaro (1954, p. 763) la distinción entre capacidad jurídica y capacidad de obrar no fue conocida como tal en el derecho romano y tampoco en el derecho español antiguo, "la recepción en España se verifica a través de los romanistas alemanes, probablemente a través de la obra De Savigny (1885, p. 40), en sus traducciones francesas, y se difunde en España por medio de la obra del profesor Sánchez Román." En nuestra opinión Savigny ya había demostrado que los romanos si conocían la distinción e incluso realizaban una graduación notable en la incapacidad de ejercicio, donde consideraban como principio fundamental que "el infante era incapaz de todo acto jurídico. El impúber, salido de la infancia, podía actuar con el consentimiento de su tutor; y sin el consentimiento de su tutor, en todos los casos en que no hubiere perjuicio ni riesgo posible. Esta segunda parte del principio se expresaba así: 'Meliorem quidem suam condicionem licere eis facere, etiam sine tutoris auctoritate, deteriorem vero non aliter quam tutore auctore'.". En concreto, y en el contexto de los menores no sujetos a auctoritas paterna, en Roma al impúber se le presumía capaz de discernimiento cuando estaba proximus pubertati, mientras que al púber se le consideraba plenamente capaz. Savigny así lo expresaba: "vemos desde los primeros tiempos de la historia que el derecho romano reconoce que el uso completo de la razón comienza con la pubertad. Antes de esta época, el hombre es incapaz de obrar, sus bienes son administrados por un tutor. A partir de esta época, teniendo plena capacidad de actuar, dispone de sus bienes y no necesita de tutor." SAVIGNY (1841) 24.

${ }^{32}$ A modo de ejemplo, en Inglaterra, el movimiento de renovación puede situarse en la década de los 80 con la dictación de la Mental Health Act de 1983, aunque el gran impulso reformador puede situarse en 2007 con la entrada en vigor de la Mental Capacity Act 2005 que pone en movimiento procedimientos y criterios para determinar la capacidad de una persona y las decisiones que pueden ser tomados en su lugar. Va acompañada de un Código de conducta para quienes trabajan con personas de capacidad limitada. La Mental Health Act 2007, sólo aporta a esta última algunas precisiones y correcciones. En Alemania, la modernización de su estatuto de mayores protegidos puede datarse en la década de los 90. La ley en vigor hasta el 31 de diciembre de 1991 disponía un régimen amplio e intrusivo de protección (incapacidad extensiva o Entmündigung y protección completa o Vormundschaft), comparable al régimen de los menores incapaces. Le Betreuungsgesetz (BtG) del 12 de septiembre de 1990 (en vigor desde $1^{\circ}$ de enero de 1992) es el punto de partida de su modernización y va a introducir cambios sustantivos en el Libro IV del BGB ( $\$ 1896$ y ss.) que incorporará un concepto menos intrusivo de protección (Betreuung), poniendo el acento en las necesidades de asistencia del adulto mayor. La década de los 90 también marcará cambios en Dinamarca, Italia, España y Suiza, que va a hacer evolucionar el Derecho civil de la capacidad y verá emerger un derecho de protección para las personas mayores vulnerables.
} 
nerables comienza con la superación, formal y de fondo, de esta tradicional división, lo que puede observarse del análisis de dos de las legislaciones de Francia e Inglaterra.

En el civil law o derecho continental, la evolución comienza en Francia, cuyo régimen fue modificado sustancialmente por primera vez por una Ley de 3 de enero de $1968^{33}$ y, luego más profundamente aún, por una Ley de 5 de marzo de $2007^{34} \mathrm{y}$, últimamente, por una Ley de 16 de febrero de $2015^{35}$ y la Ordenanza de 15 de octubre de ese mismo año ${ }^{36}$. Desde 1968, el Code ya no tratará más a las personas de incapaces -terminología considerada humillante- sino como personas protegidas.

Aunque podría decirse que, básicamente las reglas de principios (toda persona es capaz) y de excepción (sólo la ley puede determinar quiénes son incapaces) seguirán siendo las mismas, habrá una transformación evidente para adaptarse a las nuevas formas de pérdida de autonomía y dependencia (la exclusión social, las drogas, las enfermedades mentales de pérdida de memoria relacionados con la vejez) y la creciente incapacidad de las familias para hacer frente al cuidado de sus miembros vulnerables, particularmente adultos mayores. Así surgen con la Ley de 2007 los mandatarios judiciales para la protección de los adultos mayores, verdaderos profesionales de la incapacidad y se incorpora el mandato de protección futura, un mecanismo contractual de protección anticipada ${ }^{37}$. Incorpora, además, los principios de necesidad y proporcionalidad como pilares del régimen de protección, haciendo una clara distinción entre protección jurídica y protección social, todo ello a fin de lograr la protección más adaptada o adecuada posible a las necesidades del sujeto protegido. En ese orden de cosas se modifican las causas de apertura de un régimen de protección legal suprimiéndose la prodigalidad, la intemperancia o la ociosidad y, sobre todo, se establece como pilar esencial la especial consideración de la voluntad de la persona protegida a fin de permitirle escoger cuál será la persona encargada de protegerla, todo ello, además, limitando en el tiempo las medidas de protección a fin de revisar las condiciones que las provocaron. La mayor consideración de la voluntad

\footnotetext{
${ }^{33}$ Ley N ${ }^{\circ} 68-5$ de 3 de enero de 1968. Esta Ley introduciría, por ejemplo, un nuevo Art. 488 del Código civil, que se mantendría en vigor hasta 2009, que disponía: "La mayoría de edad se fija a los 18 años cumplidos; a esta edad se es capaz para todos los actos de la vida civil.

Será el mayor, sin embargo, protegido por la ley, sea con ocasión de un acto particular, sea de manera continua, cuando una alteración de sus facultades personales lo coloque en la imposibilidad de proteger solo sus intereses.

Igualmente puede ser protegido el mayor que, por su prodigalidad, su intemperancia o su ociosidad, se exponga a caer en la necesidad o comprometa el cumplimiento de sus obligaciones familiares."

${ }^{34}$ Ley $\mathrm{N}^{\circ} 2007-308$ de 5 de marzo de 2007, entrada en vigor el $1^{\circ}$ de enero de 2009.

${ }^{35}$ Ley N²015-177 de 16 de febrero de 2015, que en relación a los menores y mayores vulnerables redujo los tiempos de duración de las tutelas y curadurías.

${ }^{36}$ Ordonnance $\mathrm{N}^{\circ}$ 2015-1288 de 15 de octubre de 2015. Esta Ordenanza incluyó como dispositivo de protección la habilitación familiar.

${ }^{37}$ Ruz Lártiga (2013) "El mandato de protección futura. Mirada a una medida propuesta por el derecho civil francés para personas en situación de ser protegidas".
} 
El impacto en la legislación civil chilena de la recepción de las nociones de autonomía e independencia contenidas en la Convención Interamericana de los Derechos Humanos de las Personas Mayores

del mayor protegido, pilar esencial como viene de ser dicho, recibirá también consagración en el nuevo Art 458 del Code civil reconociendo que el mayor protegido pueda cumplir sólo, sin asistencia ni representación, actos que impliquen su consentimiento estrictamente personal, lo que consagrará la jurisprudencia de la Corte de Casación según la cual la persona protegida puede tomar por sí sola todas las decisiones que la conciernan si su estado así se lo permite ${ }^{38}$. En sentido inverso la Ordenanza de 15 de octubre de 2015 hace que la familia retome, en ciertos casos, el rol principal de protección y trae consigo un movimiento de desjudicialización del derecho de protección de las personas vulnerables, relegando la intervención del juez de tutelas.

En el common law inglés, aunque no se ha abandonado formalmente la calificación de personas capaces o incapaces, la tradición ha moldeado a la capacidad como un concepto funcional.

En efecto, el grado de incapacidad de una persona se evalúa en Inglaterra en función de las decisiones específicas que debe tomar esa persona y la hace depender de distintos factores. No existe una categoría estándar de incapacidades civiles de ejercicio ni menos una clase de sujetos que la conformen. Asimismo, no existe una lista exhaustiva de factores que causan la incapacidad, por lo que la capacidad de la persona debe ser evaluada a la luz de varios de ellos, como los efectos del dolor, los golpes y el cansancio, una enfermedad psiquiátrica, problemas de aprendizaje, demencia, daño cerebral, un estado de toxicidad causando graves enfermedades físicas que provoquen perturbaciones bioquímicas, confusión o alteración de la conciencia, etc. Como se ve, se mantiene la expresión capacidad/incapacidad, pero fuera de los moldes prestablecidos bajo la figura de categorías inamovibles.

Esta apreciación funcional de la capacidad ha sido así aplicada por los jueces ingleses quienes han expresado que: "el Derecho Inglés considera que una persona debe tener una capacidad mental necesaria para ejecutar actos o tomar decisiones que vayan a tener consecuencias legales para ella. Las autoridades están contestes en dos presupuestos básicos: en primer lugar, que la capacidad mental requerida por la ley es una capacidad ligada a cada tipo de acto que requiera ser realizado por la persona; en segundo lugar, que la capacidad requerida es la necesaria para com-

\footnotetext{
${ }^{38}$ Véase: Audience publique (4 juin 2007 y 24 février 1993), referido a la autorización de un guardador de difundir un film mostrando discapacitados mentales sin autorización de un juez de tutelas. Antes ya la Corte de Casación había sentado la doctrina según la cual el matrimonio del mayor protegido (en tutela) necesitaba precisamente de su consentimiento (Audience publique, 24 mars 1998) y confirmando esta posición recientemente (Audience publique, 2 décembre 2015). Igualmente para calificar de actos estrictamente personales los actos relativos al ejercicio de la autoridad parental del hijo del mayor protegido. (Audience publique, 6 novembre 2013).
} 
prender la naturaleza de los actos, cuando ella se ve expuesta"39. En ese contexto, la Mental Capacity Act 2005 define a las personas incapaces en relación con áreas específicas, señalando en la Sección 2.1, que "una persona es incapaz en un área, si en el momento oportuno ella no es capaz de tomar una decisión por sí misma debido a una discapacidad o un trastorno que afecte al funcionamiento de su mente o de su cerebro". La discapacidad o trastorno puede ser permanente o temporal (sección 2.2). Sin embargo, la persona se presume siempre capaz (Bartlett, 2008, p. 11) ${ }^{40}$. La misma Mental Capacity Act 2005, define "la incapacidad de tomar decisiones", señalando que una persona es incapaz de tomar decisiones si no es capaz de (i) comprender las informaciones necesarias para la toma de decisiones, (II) retener esta información, (iii) utilizar o evaluar esta información en el proceso de la toma de decisiones, o (iv) comunicar su decisión.

La apreciación funcional de la capacidad en el Derecho inglés ha permitido que, aunque se mantenga la división entre capaces e incapaces, poco o nada tenga de molde inalterable que impida actuar a las autoridades de protección determinando las medidas que proporcionalmente se puedan imponer a las personas que presenten progresivas pérdidas de autonomía decisional o incrementos de dependencia funcional.

En fin, en el orden internacional privado, una tendencia similar es posible constatar ${ }^{41}$ y en ese orden es en el que se inserta la Convención Interamericana. Pue-

\footnotetext{
${ }^{39}$ (Martin Masterman-Lister v Brutton \& Co, 2002). En este asunto el demandante apeló contra la desestimación de sus pretensiones en un asunto en el que habiendo sido resuelta una reclamación por daños y perjuicios, ahora intentaba volver a abrirla y reclamar indemnización por negligencia contra sus antiguos abogados, diciendo que no había tenido suficiente capacidad mental al momento de aceptar la proposición de reparación que se le había efectuado.

40 Los tribunales ingleses han igualmente considerado que una mujer está privada de capacidad cuando rechaza una transfusión sanguínea por razones religiosas encontrándose en su última etapa de embarazo o a una mujer que expresa fobia a las agujas al momento de dar a luz. Lo importante es remarcar que las causas de incapacidad en el derecho inglés pueden ser temporales y resultar de diferentes factores que pueden comprender el consumo excesivo de alcohol, la mala utilización de medicamentos, las perturbaciones mentales, las crisis emocionales, etc.

${ }^{41}$ Desde la Asamblea Mundial sobre envejecimiento de 1982 que adoptó el Plan de Acción Internacional de Viena sobre Envejecimiento, pasando por el Convenio de la Haya de 13 de enero 2000 "sobre la protección internacional de los adultos" que organizaría la esfera de competencias de las autoridades y designaría el derecho aplicable en caso de conflicto; luego por el Plan de Acción Internacional de Madrid sobre Envejecimiento (adoptado en la Segunda Asamblea Mundial sobre el Envejecimiento de 2002); seguido de la Convención de 2006 de las Naciones Unidas, sobre los derechos de las personas con discapacidad -calificada como el primer gran tratado de los Derechos Humanos del siglo XXIhasta el Reglamento № 606/2013 UE, del Parlamento Europeo y del Consejo de Europa, de 12 de junio de 2013 , sobre el reconocimiento mutuo de medidas de protección en materia civil, la protección internacional de los adultos vulnerables adquiere una dimensión internacional creándose, en el caso europeo, mecanismos originales para permitir la libre circulación, en el espacio judicial civil europeo, de los principales dispositivos de protección para los mayores
} 
El impacto en la legislación civil chilena de la recepción de las nociones de autonomía e independencia contenidas en la Convención Interamericana de los Derechos Humanos de las Personas Mayores

de concluirse, entonces, que si una de las tendencias, en Europa ${ }^{42}$, desde hace casi tres décadas ha sido la de superar la división entre personas capaces e incapaces ${ }^{43}$, es visualizable, si ha de seguirse ese camino, el impacto que la introducción de las nociones de autonomía e independencia, consagradas por la Convención, traerá en el estado actual de protección jurídico-privada de los adultos mayores vulnerables en Chile. En efecto, esta evolución pone en evidencia la paradoja sobre la que se sustenta nuestro sistema de protección jurídico-privado en sede civil: en principio, las personas que van progresivamente perdiendo autonomía decisional e incrementan su dependencia funcional en razón de su gran edad, carecen de toda protección civil,

\footnotetext{
${ }^{42}$ Y que ha alcanzado por lo demás a América Latina (Uruguay, Ley № 17.796, de 19 de agosto de 2004, sobre promoción integral de los adultos mayores; Perú, Ley N³0.490, de 21 de julio de 2016, de la persona del adulto mayor; Ecuador, Ley $\mathrm{N}^{\circ} 127$, de 6 de noviembre de 199, Ley Especial del Anciano). En Argentina, donde la regulación del Código civil y comercial de la nación (Libro I, Capítulo II, Arts. 22 a 50) es digna de imitar, destaca el Art. 32 que dispone: "(inc. $1^{\circ}$ ) Persona con capacidad restringida y con incapacidad. El juez puede restringir la capacidad para determinados actos de una persona mayor de trece años que padece una adicción o una alteración mental permanente o prolongada, de suficiente gravedad, siempre que estime que del ejercicio de su plena capacidad puede resultar un daño a su persona o a sus bienes. (Inc. $2^{\circ}$ ) En relación con dichos actos, el juez debe designar el o los apoyos necesarios que prevé el artículo 43, especificando las funciones con los ajustes razonables en función de las necesidades y circunstancias de la persona. (Inc. $3^{\circ}$ ) El o los apoyos designados deben promover la autonomía y favorecer las decisiones que respondan a las preferencias de la persona protegida. (Inc. $4^{\circ}$ ) Por excepción, cuando la persona se encuentre absolutamente imposibilitada de interaccionar con su entorno y expresar su voluntad por cualquier modo, medio o formato adecuado y el sistema de apoyos resulte ineficaz, el juez puede declarar la incapacidad y designar un curador." Otro buen ejemplo es Brasil cuyo Estatuto do Idoso "Estatuto Nacional de los Adultos Mayores" (Ley 10.741, de 1 de octubre de 2003) tiene por objetivo regular los derechos especiales de las personas mayores de sesenta años y de establecer derechos fundamentales y de ciudadanía, así como de asistencia judicial. Ariston Barion Pérès, A. P., y Fossier, T. (2005), exponen comparativamente los estatutos de los mayores adultos vulnerables en Francia y en Brasil, concluyen que el Estatuto do Idoso reposa sobre una presunción de debilidad más que en una prueba formal de vulnerabilidad, lo que conduce a evitar el recurso frecuente a la incapacitación (interdicción) civil. En Centroamérica, fuera de México y su Ley de Derechos de las Personas Adultas Mayores de 25 de junio de 2002, Costa Rica, a partir de 1988, ha desplegado un enorme dispositivo legislativo y reglamentario de protección al adulto mayor donde destaca la Ley Integral para la Persona Adulta Mayor de 1999 (Ley N7935). Caso destacable en sede civil-privada es Cuba, donde las personas especialmente vulnerables reciben en el propio Código civil y en materia sucesoria protección del legislador, bajo la figura del "heredero especialmente protegido". Así, por ejemplo, el Art. 493 del Código civil Cubano dispone que: "(Inc. $1^{\circ}$ ) Son herederos especialmente protegidos, siempre que no estén aptos para trabajar y dependan económicamente del causante, los siguientes: a) los hijos o sus descendientes en caso de haber premuerto aquellos; b) el cónyuge sobreviviente; y c) los ascendientes. (Inc. $2^{\circ}$ ) 2. Si concurren a la herencia dos o más herederos especialmente protegidos, heredan por partes iguales." El Art. 492 a su vez dispone "(Inc. $1^{\circ}$ ) La libertad de testar se limita a la mitad de la herencia cuando existen herederos especialmente protegidos. (Inc. $2^{\circ}$ ) 2. El testador no puede imponer gravamen alguno a la porción de la herencia que corresponde a los herederos especialmente protegidos". En sede ab intestato, el Art. dispone que: "Los padres no aptos para trabajar y que dependían económicamente del causante, concurren con los descendientes de éste y el cónyuge sobreviviente y heredan una porción igual a la de aquellos". Delgado Vergara (2010); Pereira Pérez (2013).

${ }^{43}$ Es el caso de Francia en 1968, Suecia en 1989 y Alemania 1991 que tomaron la decisión de eliminar la nomenclatura. Francia la reemplazaría por la expresión "personas protegidas", mientras que Suecia y Alemania optaron por "causas de tutela". La Europa de los nuevos países integrados (aquellas que estaban bajo la antigua influencia soviética) aún mantienen sus sistemas basados en la categorización de capaces e incapaces, pero ya están sufriendo cambios como consecuencia de su integración a la Unión Europea, siendo el principal representante de este movimiento modernizador la República Checa.
} 
pues el Código las reconoce plenamente capaces. Luego, para recibir la protección de la ley, no hay otro camino que incapacitarlas mediante un procedimiento judicial de interdicción, lo que conduce a un atentado a su dignidad como personas, al desconocerles estos derechos fundamentales al respeto de su autonomía e independencia.

El primer camino, entonces, pareciera estar señalizado y plantea la cuestión de superar la división binaria entre personas capaces e incapaces, sea liberándola de sus moldes preestablecidos, sea reconociendo en nuestra legislación estados intermedios de pérdida de capacidad, asociados a regímenes adecuados de protección. El segundo camino pareciera ser consecuencia del primero, y se presenta como la necesidad de modificar un régimen de protección basado sólo en la incapacitación (y la declaración de interdicción) y crear distintos grados o mecanismos de protección proporcionales a la pérdida de autonomía e independencia del adulto mayor vulnerable. Este segundo camino exige, entonces, una revisión del régimen de las guardas vigente en Chile.

\subsection{Hacia una necesaria revisión del régimen de las guardas vigentes en Chile}

El sistema de protección de incapaces en Chile data de los inicios de nuestro decimonónico Código civil. Desde su entrada en vigencia el régimen de las guardas, consagrado extensamente en 14 Títulos del Libro Primero (Títulos XIX al XXXII), no ha sido sustancialmente modificado ${ }^{44}$. La consecuencia evidente de esta vetusta regulación es que las tendencias de los últimos 30 años en Europa no tienen cabida producto de las rigideces que presenta nuestra regulación. Así como ha quedado dicho que una de las tendencias en el viejo continente desde hace casi tres décadas ha sido la de superar la división entre personas capaces e incapaces, otra marcada tendencia han sido la de eliminar el sistema de protección basado únicamente en la declaración de interdicción ${ }^{45}$, disponiéndose sea de un abanico de medidas adaptadas a los distintos grados de pérdida de autonomía y dependencia, todo ello con pleno respeto de la dignidad de la persona protegida ${ }^{46}$, sea a través de otorgarle al juez el campo

\footnotetext{
${ }^{44}$ Las modificaciones que han sufrido estos títulos han sido tangenciales y provocadas por 19 leyes que han atacado otros institutos del Código civil (Ley №5.521 de 1934; Ley №.612 de 1943; Ley $\mathrm{N}^{\circ} 10.271$ de 1952; Ley 18.776 y №18.802 de 1989; Ley 19.221 de 1993; Ley №19.585 de 1998; Ley 19.904 de 2003 y Ley $N^{\circ} 19.947$ de 2004).

45 Es el caso de Alemania y Suecia que eliminaron la declaración de interdicción y recurren a un régimen de protección único, pero flexible, pudiendo adaptarse a distintas situaciones individuales con soluciones o medidas judiciales o administrativas proporcionales a los distintos grados de pérdida de autonomía y dependencia.

${ }^{46}$ Es el caso de Francia e Inglaterra cuyo propósito es reducir al mínimo las limitaciones de la capacidad de administrar sus propios asuntos a los mayores protegidos. Lo mismo puede decirse de España que en Art. 267 del Código Civil permite la posibilidad de graduar la capacidad al disponer: "El tutor es
} 
El impacto en la legislación civil chilena de la recepción de las nociones de autonomía e independencia contenidas en la Convención Interamericana de los Derechos Humanos de las Personas Mayores

de acción necesaria para graduar la capacidad de la persona protegida detallando los actos que pueda pasar por sí sola.

A modo ejemplar, el Art. 425, inciso $1^{\circ}$ del Código civil francés abre la posibilidad de decretar medidas de protección para "toda persona que se encuentre en la imposibilidad de proteger sola sus intereses producto de una alteración, médicamente constatada, sea de sus facultades mentales, sea de sus facultades corporales, que le impidan expresar su voluntad"47. En nuestro continente, otra tendencia puede detectarse en Argentina donde conservando la distinción, el Art. 32 del Código civil y comercial de la Nación ${ }^{48}$, permite al juez graduar la capacidad de la persona para la realización de determinados, relegando la declaración de interdicción como última ratio o extrema solución ${ }^{49}$. Estos dos ejemplos ponen de manifiesto que, en la necesaria reformulación de nuestro régimen de protección para aquellas personas que, siendo capaces, no pueden plenamente dirigirse a sí mismos o administrar competentemente sus negocios, por encontrarse en un especial estado de vulnerabilidad asociado a su gran edad, la definición de un modelo de protección será determinante.

No hay uno sino varios modelos jurídicos de protección. Intentar sistematizarlos todos excedería evidentemente los propósitos de este trabajo. La evidencia, sin embargo, recoge modelos fundados en la mantención de la summa divisio de capaces e incapaces, sobre la base de la declaración de interdicción judicial, pero otorgándole al juez la facultad de graduar o limitar la incapacidad de la persona en razón de su capacidad para tomar decisiones ${ }^{50}$; otros fundados sobre una variedad de me-

el representante del menor o incapacitado salvo para aquellos actos que pueda realizar por sí solo, ya sea por disposición expresa de la ley o de la sentencia de incapacitación".

${ }^{47}$ Art. 425. "Toute personne dans l'impossibilité de pourvoir seule à ses intérêts en raison d'une altération, médicalement constatée, soit de ses facultés mentales, soit de ses facultés corporelles de nature à empêcher l'expression de sa volonté peut bénéficier d'une mesure de protection juridique prévue au présent chapitre. (Inc. $1^{\circ}$ \%. S'il n'en est disposé autrement, la mesure est destinée à la protection tant de la personne que des intérêts patrimoniaux de celle-ci. Elle peut toutefois être limitée expressément à l'une de ces deux missions. » (Inc. $\left.2^{\circ}\right)$.

${ }^{48}$ Art 32. "(Inc. $\left.1^{\circ}\right)$ Persona con capacidad restringida y con incapacidad. El juez puede restringir la capacidad para determinados actos de una persona mayor de trece años que padece una adicción o una alteración mental permanente o prolongada, de suficiente gravedad, siempre que estime que del ejercicio de su plena capacidad puede resultar un daño a su persona o a sus bienes. (Inc. $2^{\circ}$ ) En relación con dichos actos, el juez debe designar el o los apoyos necesarios que prevé el artículo 43, especificando las funciones con los ajustes razonables en función de las necesidades y circunstancias de la persona. (Inc. $3^{\circ}$ ) El o los apoyos designados deben promover la autonomía y favorecer las decisiones que respondan a las preferencias de la persona protegida. (Inc. $4^{\circ}$ ) Por excepción, cuando la persona se encuentre absolutamente imposibilitada de interaccionar con su entorno y expresar su voluntad por cualquier modo, medio o formato adecuado y el sistema de apoyos resulte ineficaz, el juez puede declarar la incapacidad y designar un curador."

${ }^{49}$ Fernández (2012) y Rajmil y Llorens(2015).

${ }^{50}$ La legislación inglesa prevé distintos grados de incapacidad evaluados en función de la capacidad de tomar ciertas decisiones, de manera que para que sea declarada incapaz la persona debe encontrarse en la imposibilidad de comprender las consecuencias razonablemente previsibles de una decisión o de una negativa a decidir. La Mental Capacity Act 2005 (section 20.1) dispone, además, que cuando el tutor nombrado por el tribunal tiene razones suficientes para creer que el protegido ha 
canismos de protección (judiciales y contractuales) relegando la declaración de interdicción a última ratio ${ }^{51}$; otros que han suprimido la declaración de interdicción y han abrazado un régimen único de protección, pero flexible, que puede ser adaptado a las situaciones individuales de cada sujeto protegido y extenderse a uno o varios actos jurídicos relativos a la persona o patrimonio del interesado ${ }^{52}$; o, en fin, otros modelos -como el nuestro- que mantienen un catálogo preestablecido de personas incapaces ya sea de pleno derecho o que pasan a serlo una vez declarados interdictos, pero en todos los casos bajo la figura de la declaración judicial de interdicción. Lo que sí parece definitivamente desterrado son los modelos que plantean formalmente tertius conceptus, incluyendo una categoría intermedia como la de personas semicapaces o semi-incapaces, como una suerte de "incapacidades de los capaces", como lo sostiene la profesora Brandi Taiana (2004) ${ }^{53}$.

recobrado la capacidad de tomar decisiones, el tutor pierde el poder de decidir por él. Otro ejemplo es España donde el juez en la sentencia de incapacitación puede numerar aquellos actos que el protegido pueda realizar por sí sólo. En ambas legislaciones se reconoce, en el orden extrajudicial, el mandato de protección futura.

${ }^{51}$ Francia reconoce como mecanismos la tutelle, que es la medida más incapacitante de todas, implica representación de un tutor, aunque se reconoce a la persona protegida autonomía y capacidad para realizar por sí misma los actos que la ley, la costumbre o el juez determinen (los actos que implican un consentimiento estrictamente personal según los Arts. 458 y 459 del Code; la curatelle que es una medida de incapacitación intermedia que implica asistencia y consejo (autorización) de un curador (admite graduación en curatela simple, extendida y reforzada); la sauvegarde de justice que es una medida de protección provisoria donde el protegido mantiene plena capacidad jurídica y puede decretarse con o sin la designación de un mandataire en justice para la realización de ciertos actos; La mesure d'accompagnement judiciaire (MAJ) que es una medida de protección a favor de una persona que pone en peligro sus intereses sin padecer, sin embargo, de alteraciones personales. Es una medida a la vez de protección y de asistencia educativa pues busca ayudar a la persona a retomar su autonomía en la gestión de su patrimonio; la habilitation familiale, que es un dispositivo difícil de clasificar pero que implica a la familia próxima del protegido, puede ser parcial o total, cubrir sólo ciertas prerrogativas o facultades o todas, lo que lleva a la persona autorizada a ser, ya sea un representante legal con amplias facultades, ya sea una suerte de mandatario con poderes limitados al ejercicio de ciertos derechos expresados en la resolución de nombramiento. En el orden extrajudicial o contractual reconoce, por un lado, la mesure d'accompagnement social personnalisé (MASP) que es un contrato que celebra la autoridad departamental con el interesado que padece de dificultades para administrar, conforme a su interés, las prestaciones sociales que recibe y, por el otro, el mandato de protección futura.

${ }^{52}$ Alemania prevé sólo la tutela (Betreuung), en la cual el protegido no pierde jamás su capacidad, y que permite diferentes grados de extensión de la protección dependiendo del estado mental del adulto y de los riesgos ligados a eventuales acciones independientes. Generalmente admite dos grados la total (Totalbetreuung) o la limitada (Teilbetreuung), Conforme lo dispone el § 1896 BGB, los poderes del tutor están sujetos a muchas restricciones y la extensión de estos debe ser claramente determinada por el juez para cada caso en particular. En el orden extrajudicial también se reconoce el mandato de protección futura.

${ }^{53}$ Destaca que "dentro del mundo de los 'capaces', muchas veces nos enfrentamos con las 'incapacidades de los capaces'. Todo ser humano tiene aspectos de su vida y su personalidad para los que no es hábil y en los que la noción de 'autogobierno' es seriamente cuestionable. El tema debe ser encarado al revés de lo que podríamos pensar: no desde lo jurídico hacia lo humano sino desde lo humano a lo jurídico. Reconocida la 'incapacidad de los capaces y la capacidad de los incapaces' en el mundo 'metajurídico', debemos repensar los sistemas normativos que ofrecemos a esta realidad y no viceversa; el derecho debe estar al servicio del hombre y no el hombre al servicio de la ley."(p. 5) 
El impacto en la legislación civil chilena de la recepción de las nociones de autonomía e independencia contenidas en la Convención Interamericana de los Derechos Humanos de las Personas Mayores

Un sistema, entonces, como el que se contiene en nuestro Código civil, sumido en un numerus clausus de incapaces, que no da la debida protección a estados intermedios que requieren de protección legal, estará expuesto, en las condiciones que establece la Convención, a ser denunciado.

Cualquiera sea el modelo que se escoja para reorientar la regulación civil en Chile de la capacidad y la protección asociada a la pérdida de ésta, pareciera que debe orientarse sobre la base de ciertos principios fundamentales y de determinadas condiciones que deben presentarse para jerarquizar los distintos mecanismos o grados de protección.

En lo que concierne a los principios fundamentales, un buen ejemplo es el régimen de personas protegidas en Francia que se erige sobre la base de tres principios fundamentales: El principio de necesidad, el de subsidiaridad y el de proporcionalidad. El primero, que subyace en toda la reglamentación, pone de manifiesto que cualquiera medida de protección exige la constatación profesional (médica o psicológica) del estado de especial vulnerabilidad del mayor adulto, unido a la estimación de su evolución previsible y de las consecuencias para éste de la necesidad de ser asistido o representado. El segundo, consagrado más explícitamente (Art. 428 del Code $^{54}$ ) expresaría que las reglas de protección, dado su carácter especial, se aplicarán sólo cuando las reglas del derecho común de la representación, las reglas sobre derechos y deberes entre cónyuges, las de los regímenes matrimoniales, o la técnica del mandato de protección futura, no otorguen la protección necesaria. La idea de subsidiariedad se manifiesta, además, en que cada dispositivo de protección se aplica cuando el de menor intensidad no asegura una protección suficiente. El tercero, evocado en el inciso final del Art. 428 del Code, expresa que toda medida debe ser proporcionada e individualizada en función del grado de alteración de las facultades personales del interesado. En el caso de la curatela el juez en todo momento puede enunciar los actos que el protegido es capaz de realizar por sí solo o aquellos que requiere de asistencia del curador.

En cuanto a las condiciones que deben presentarse para otorgar la adecuada protección legal, éstas dependerán de una serie de factores, como la duración de la alteración volitiva, los factores de salud asociados, el carácter pasajero o definitivo, parcial o completo, de estas alteraciones o factores, entre otras. La graduación de las medidas de protección deberá reconocer necesariamente la capacidad natural del

\footnotetext{
${ }^{54}$ Art. 428. "La mesure de protection ne peut être ordonnée par le juge qu'en cas de nécessité et lorsqu'il ne peut être suffisamment pourvu aux intérêts de la personne par l'application des règles du droit commun de la représentation, de celles relatives aux droits et devoirs respectifs des époux et des règles des régimes matrimoniaux, en particulier celles prévues aux articles 217, 219, 1426 et 1429, par une autre mesure de protection judiciaire moins contraignante ou par le mandat de protection future conclu par l'intéressé. (Inc. $1^{\circ}$ ). La mesure est proportionnée et individualisée en fonction du degré d'altération des facultés personnelles de l'intéressé." (Inc. $2^{\circ}$ ).
} 
individuo, es decir, un cúmulo de actos de carácter estrictamente personales que puedan ser ejecutados o celebrados por la persona protegida, sin necesidad de asistencia o representación de un tercero.

En ese contexto, un paso importante se podría dar en el caso chileno, sin implicar una modificación que transforme completamente el sistema actual, pero que definitivamente lo modernice, acogiendo los distintos grados de pérdida de autonomía decisional y dependencia funcional. En efecto, sobre ese escenario, podríase mantener la declaración de interdicción judicial y la consiguiente incapacitación total de la persona, pero relegada como medida extrema, sólo para los casos en que el grado de pérdida de autonomía e independencia, causado por una alteración física o psíquica grave, vuelva a la persona especialmente vulnerable en términos que le imposibilite seriamente poder expresar su voluntad, en cualquier forma que sea, o la exponga a abusos o a riesgos elevados de sufrir daños en su persona o bienes, y siempre que los otros dispositivos de protección de menor intensidad resulten ineficaces para darle la debida protección. De ese modo, la incapacitación quedaría como medida de protección máxima, para casos graves de pérdida de autonomía decisional o dependencia funcional ${ }^{55}$, y que operaría mediante la técnica de la representación que se encargaría a un tercero designado por el propio protegido, anticipadamente, cuando se encontraba en situación de poder hacerlo, o por el juez, de entre las personas que el legislador considere dignas para esta tarea, procurando siempre, en este caso y en la medida que sea posible, considerar la voluntad del protegido en la elección. Para la eficacia de este dispositivo, siempre de carácter temporal, una revisión periódica de las causas que llevaron a decretarla y su necesidad de mantenerlas en el tiempo, sumado a una revisión estricta de la gestión patrimonial del protegido, son imprescindibles.

La curatela podría, en este mismo escenario, mantenerse como medida de menor intensidad, que reposaría en una presunción de capacidad de la persona protegida, y que se abriría o concedería para casos menos graves de pérdida de autonomía decisional o dependencia funcional, extendiéndose los ámbitos o áreas de protección, con mayor o menor intensidad, dependiendo del grado de pérdida de autonomía o de dependencia del mayor adulto vulnerable, confiriéndole al juez la facultad de determinar qué actos o contratos podrá ejecutar o celebrar el protegido por sí mismo y cuáles deberá ejecutar o celebrar asistido por un tercero que lo represente, autorice, refrende o simplemente confirme sus actos. En la elección de este tercero de apoyo, los mismos pilares anteriores deberían observarse por el juez, así como el carácter temporal de la medida y la exigencia de revisión periódica de las

\footnotetext{
${ }^{55}$ Como lo concluye Massip (2003) “... la tutela no debería entonces ser aplicada sino a las formas más profundas de alteración de las facultades de un individuo (enfermedades mentales de grave alcance, adultos mayores si posibilidad de actuar)" (p. 336).
} 
El impacto en la legislación civil chilena de la recepción de las nociones de autonomía e independencia contenidas en la Convención Interamericana de los Derechos Humanos de las Personas Mayores

causas que llevaron a decretarla y su necesidad de mantenerlas en el tiempo, amén de un control estricto de la gestión patrimonial del protegido que se le haya encargado al curador.

La curatela podría concebirse como sistema único de protección de personas capaces pero vulnerables, encargándosele al juez la intensidad de las restricciones a la capacidad de la persona y el grado de intervención del curador o bien graduarse en estándares más o menos amplios (curatela simple, moderada, reforzada, etc.) siempre que en cada categoría se permita al juez ampliar o restringir el ámbito o áreas de protección.

La mantención de ambos mecanismos se propone simplemente como un ejercicio que mantendría el sistema actual de medidas de protección con el fin de mantener también una tradición que, en el sobrevuelo que se ha hecho de las experiencias comparadas, es perfectamente posible preservar. Evidentemente que esta proposición pasa por el convencimiento de que debe superarse la summa divisio de capaces e incapaces bajo los moldes rígidos que existen hoy, es decir, bajo categorías de personas que por el sólo hecho de caer en alguna de éstas son consideradas incapaces absoluta o relativamente ${ }^{56}$.

Cada una de estas medidas debe ir acompañada de la correspondiente publicidad de las decisiones, procurando no lesionar la dignidad del mayor protegido. Una anotación marginal en el acta de nacimiento del mayor protegido podría bastar para producir efectos respecto de terceros.

Ciertamente que la posibilidad de modificar más profundamente las reglas de protección actualmente vigentes, sea importando variados mecanismos de protección, como en el caso francés, o concretamente optando por un sistema único de protección, como en el caso alemán, es también factible, sin embargo se avizora que una modificación de esta naturaleza sería más lenta y difícil de consensuar entre nuestros legisladores.

En fin, el impulso modernizador debería lógicamente llevar a la apertura de nuestro legislador a introducir cambios en materias de protección del consentimiento en la etapa de formación de los actos jurídicos que ejecuten adultos mayores vulnerables (revisando, por ejemplo, el nuevo régimen de la fuerza como vicio de la voluntad en el Derecho francés ${ }^{57}$ ) o tipificando nuevas prohibiciones en relación a los

\footnotetext{
${ }^{56}$ En Francia el Art. 1146 del Code, ha mantenido la categoría de incapaces para los efectos de la contratación, pero no en términos rígidos: "Son incapaces de contratar, en la forma definida por la ley: $1^{\circ}$ Los menores no emancipados; $2^{\circ}$ Los mayores protegidos en los términos del Art. 425."

${ }^{57}$ Art. 1143 del Code, nacido de l'Ordonnance №2016-131 del 10 de febrero de 2016: "Existe igualmente fuerza cuando una parte, abusando del estado de dependencia (vulnerabilidad) en el cual se encuentra su cocontratante, obtiene de éste un compromiso que no hubiera adquirido sin la presencia de tal presión y de la cual obtiene una ventaja manifiestamente excesiva." Una regulación similar puede ya encontrarse en
} 
actos entre vivos con personas que pueden influir en las decisiones de estos adultos vulnerables (como en el caso del antiguo Art. 1125-1 del Code ${ }^{58}$ ) o estableciendo nuevas incapacidades para suceder tratándose de actos mortis causa (como en el caso del Art. 909 del mismo $\operatorname{Code}^{59}$ ). Esta parte del análisis ameritaría claramente un trabajo aparte y de mayor extensión.

\section{Conclusiones}

La entrada en vigencia de la Convención exigirá a Chile la realización de cambios en su legislación civil-privada. En sede de Código civil se deberá conciliar las disposiciones relativas a la capacidad y sus reglas de protección con esta segmento etario protegible, atendida su especial vulnerabilidad, con las nociones de autonomía e independencia erigidas como derechos fundamentales de los adultos mayores.

Ambas nociones son recepcionadas por la Convención con contornos jurídicos que permiten una definición bastante clara de su sentido y alcance, es decir de su perímetro de acción: autonomía decisional y dependencia funcional física. Ambas nociones han de integrarse en una dinámica relacional en sede civil privada.

El reconocimiento de ambas nociones provocará un impacto considerable en las reglas de la capacidad del Código civil, las que deberán abandonar la summa divisio estática y categorial, entre personas capaces e incapaces que allí se contiene. La tendencia en la experiencia comparada sigue esa línea.

Consecuencialmente, el sistema de protección de la incapacidad o régimen de guardas, basado sólo en la incapacitación (y la declaración de interdicción), deberá ser revisado a fin de dar la debida protección a los adultos mayores especialmente

el Derecho civil alemán (\$138 BGB), suizo (Art. 21 C. de las obligaciones), italiano (Art. 1448 CC) o danés (Art. 31 Ley sobre los contratos), entre varios otros. Regulaciones similares sancionando este tipo de comportamientos, aunque no calificables de violencia sino de lesión, se pueden encontrar en los Principios Unidroit (Art 3.10), Los principios de Derecho Europeo de los contratos (Art 4:109) y el Código Europeo de los Contratos (Art 156).

${ }^{58}$ El ex Art 1125-1 del Code (creado por la Ley de 1968 y derogado a partir del $1^{\circ}$ de octubre de 2016), prohibía, salvo autorización judicial previa, y bajo sanción de nulidad, a cualquiera persona que ejerciera una función o empleo en un establecimiento de larga estadía (asilos o casas particulares) o en establecimientos de salud psiquiátricos, de adquirir, por sí o por interpósita persona, bienes o aceptar derechos pertenecientes a las personas admitidas en esos establecimientos o a tomar en arrendamiento el inmueble que ocupa el mayor protegido antes de su admisión en el establecimiento.

${ }^{59}$ El Art. 909 del Code, prohíbe, salvo excepciones, a los profesionales de la salud (incluidos farmacéuticos) y no profesionales-auxiliares (incluye a mandatarios judiciales y religiosos) de recibir donaciones y herencias o legados, respecto de estas personas a quienes hayan atendido en la enfermedad que le causó la muerte. 
El impacto en la legislación civil chilena de la recepción de las nociones de autonomía e independencia contenidas en la Convención Interamericana de los Derechos Humanos de las Personas Mayores

vulnerables que, sin ser incapaces, no pueden sin embargo dirigirse plenamente a sí mismos o administrar competentemente sus negocios.

Cualquier sistema que se abrace para cumplir esta tarea deberá procurar dar la protección debida a este segmento etario sobre la base de pilares o principios fundamentales (necesidad, subsidiaridad y proporcionalidad) con pleno respeto de su dignidad como personas, sus libertades individuales y de los derechos fundamentales (autonomía e independencia) que establece la Convención.

\section{Agradecimientos}

El presente artículo forma parte del Proyecto de investigación interno titulado: “La protección jurídico-privada del mayor vulnerable en el derecho civil chileno y comparado", en el cual el autor es investigador principal.

\section{Referencias Bibliográficas}

Ariston Barion Pérès, A. P., y Fossier, T. (2005). Vulnérabilité ou affaiblissement : quel statut civil pour la personne âgée ? Les exemples français et brésilien. Droit de la famiIle, (10), 12-14. Recuperado de http://bit.ly/2IEwd4k

Audience publique du lundi 4 juin 2007, 05-20243 (Première chambre civile de la Cour de cassation française). Recuperado de http://bit.ly/2IMfU5F

Audience publique du mercredi 2 décembre 2015, 14-25777 ECLI:FR:CCASS:2015:C101364 (Première chambre civile de la Cour de cassation française). Recuperado de http://bit.ly/2kFIAhG

Audience publique du mercredi 24 février 1993, 91-13587 (Première chambre civile de la Cour de cassation française). Recuperado de http://bit.ly/2IKzGhW

Audience publique du mardi 24 mars 1998, 97-11252 (Première chambre civile de la Cour de cassation française). Recuperado de http://bit.ly/2ILKVa1

Audience publique $d u$ mercredi 6 novembre 2013, 12-23766 ECLI:FR:CCASS:2013:C101233 (Première chambre civile de la Cour de cassation française). Recuperado de http://bit.ly/2khpsp2

Barrientos Grandón, J. (2016). El código civil, su jurisprudencia e historia (Vols. 1-2). Santiago: Thomson Reuters. 
Bartlett, P. (2008). Blackstones guide to the mental capacity act 2005 (2a ed.). Oxford: Oxford University Press.

Brandi Taiana, M. M. (2004). Apuntes sobre los conceptos de capacidad e incapacidad en el derecho español y argentino [PDF]. Buenos Aires: Astrea. Recuperado de http://bit.ly/2kfLgBm

Desvaux-Bernheim, S. (2010). La difficile conciliation de l'autonomie et de la protection de la personne vulnérable. Revue juridique personnes et famille, (4), 8-10.

Casso y Romero, I. de, \& Cervera y Jiménez-Alfaro, F. (Eds.). (1954). Diccionario de derecho privado (Vol. 1). Barcelona: Labor.

Castel, R. (2010). L'autonomie, aspiration ou condition? La vie des idées. Recuperado de http://bit.ly/2kw9bMQ

Chile, Ministerio de Justicia. (2015). Código civil. Recuperado de http://bcn.cl/1uu74

Cornu, G. (2005). Vocabulaire juridique (7a ed.). Paris: PUF.

D' Alton, A. (2009). La notion d'autonomie personnelle en droit européen des droits de l'homme, approche de philosophie du droit. Droit Prospectif: Revue de la Recherche Juridique, 34(129). Recuperado de http://bit.ly/2kwq36g

DeJong, G. (1979). Independent living: from social movement to analytic paradigm. Archives of physical medicine and rehabilitation, 60(10), 435-446. Recuperado de http://bit.ly/2lySCjD

Delgado Vergara, T. (2016). Vulnerabilidad y dependencia en la madurez de la vida: apuntes sobre la protección a las personas de la tercera edad en Cuba. Revista ius, 4(26), 140-155. https://doi.org/10.35487/rius.v4i26.2010.237

Demogue, R. (1911). Les notions fondamentales du droit privé: essai critique, pour servir d'introduction à l'étude des obligations. Paris. Recuperado de https:// http://bit.ly/2llckJP

De Savigny, F. C. von. (1855). Traité de droit romain. (C. Guénoux, Trad.) (Vol. 2). Paris: Librairie de Firmin Didot Frères. Recuperado de http://bit.ly/2kcGyEm

Dorn Garrido, C. (2011). La dignidad de la persona: Límite a la autonomía individual. Revista de derecho - Consejo de Defensa del Estado, (26), 71-108. Recuperado de http://bit.ly/2kwagEx 
El impacto en la legislación civil chilena de la recepción de las nociones de autonomía e independencia contenidas en la Convención Interamericana de los Derechos Humanos de las Personas Mayores

Dutheil-Warolin, L. (2004). La notion de vulnérabilité de la personne physique en droit privé (thèse de doctorat). Université de Limoges, Limoges, France. Recuperado de http://bit.ly/2ko5j0D

Ennuyer, B. (2003). Histoire d'une catégorie: "personnes âgées dépendantes". En C. Martin (Ed.), La dépendance des personnes âgées. Quelles politiques en Europe? (pp. 95114). Rennes: Presses universitaires de Rennes. https://doi.org/10.4000/books.pur.14911

Ehrenberg, A. (2010.) La société du malaise. Paris: Odile Jacob.

Ehrenberg, A. (2010b). Société du malaise ou malaise dans la société? La vie des idées. Recuperado de http://bit.ly/2m4X35U

Favier, Y. (2012). Vulnérabilité et fragilité face au vieillissement: I'approche du droit français. Revista kairós, 15(6), 61-68. Recuperado de: http://bit.ly/2m6B9zl

Fernández, S. (2012). Ancianidad, autonomía y vulnerabilidad. Una mirada a la situación jurídica de los adultos mayores desde la reforma proyectada para el Código Civil argentino. Revista derecho privado, 1(2), 139-164. Recuperado de http://bit.ly/2k7C6qq

Fietcher-Boulvard, F., \& . (2000). La notion de vulnerabilité et sa consécration par le droit . En F. Cohet-Cordey (Coord.), Vulnérabilité et droit. Le développement de la vulnérabilité et ses enjeux en droit (pp. 13-32). Grenoble: PUG. Recuperado de http://bit.ly/2kqcMMG

France. (2007). Code civil. Recuperado de http://bit.ly/2km2M6W

García Martínez, A. (2001) La cuestión de la dependencia en la vejez, Pedagogía social, Revista Interuniversitaria, (8), 255-264.

Goldfarb, M. (2016, February 25). Los adultos mayores como sujetos vulnerables (a propósito de la Convención interamericana sobre la protección de los derechos humanos de las personas mayores). El derecho. Diario de doctrina y jurisprudencia. Recuperado de http://bit.ly/2m5SWGN

González, M., Massad, C., Lavanderos, F., Albala, C., Sánchez, H., Fuentes, A.,... Quijada, S. (Sin fecha). Estudio nacional de dependencia en las personas mayores. SENAMA: Santiago. Recuperado de http://bit.ly/2m9QYVZ

Gzil, F. (2009) La maladie d'Alzheimer: problèmes philosophiques. Paris: PUF.

Gzil, F., Rigaud, A.-S., \& Latour, F. (2008). Démence, autonomie et compétence. Éthique Publique, 10(2). https://doi.org/10.4000/ethiquepublique.1453 
Hauser, J. (2011). Une théorie générale de la protection du sujet vulnérable?. Revue lamy droit civil, (83), 69-73.

Hauser, J. (2012). La distinction des actions personnelles et des actions patrimoniales à l'épreuve du droit des personnes protégées. En F. Bicheron et al. (Ed.), Mélanges en I'honneur du professeur Gérard Champenois (pp. 441-452). Paris: Défrenois.

Hugo, V. (1865) Les misérables. Paris: J. Hetzel y A. Lacroix, Editeurs.

Hurpy, H. (2015). Fonction de lautonomie personnelle et protection des droits de la personne humaine dans les jurisprudences constitutionnelles et européenne. Bruxelles: Bruylant.

La protección internacional de las personas dependientes. (2014). Manuscrito no publicado, Universidad Carlos III de Madrid. Recuperado de http://bit.ly/2ILSZaN

Lacour, C. (2007). Vieillesse et vulnérabilité. Aix-en-Provence: Presses Universitaires d'Aix-Marseille.

Lacour, C. (2009). La personne âgée vulnérable: entre autonomie et protection. Gérontologie et société, 32(131), 187-201. https://doi.org/10.3917/gs.131.0187

Lathrop, F. (2009). Protección jurídica de los adultos mayores en Chile. Revista chilena de derecho, 36(1), 77-113. https://doi.org/10.4067/s0718-34372009000100005

Lavaud-Legendre, B. (2010.) La paradoxale protection de la personne vulnérable par elle-même: les contradictions d'un "droit de la vulnérabilité" en construction. Revue de droit sanitaire et social, (3), 520-534.

León Hurtado, A. (1963). La voluntad y la capacidad en los actos jurídicos, 2a ed. Santiago: Editorial jurídica de Chile.

Levinet, M. (2009). La notion d'autonomie personnelle dans la jurisprudence de la Cour européenne des droits de l'homme. Paris: Presses universitaires de France.

Mallet, E. (2014). Actes à consentement strictement personnel et majeur protégé. Droit de la famille, (3), 17-19.

Maria, I. (2016). Les actes strictement personnels: véritable raz-de-marée au pays des majeurs protégés!. Droit de la famille, (2), 28-36. 
El impacto en la legislación civil chilena de la recepción de las nociones de autonomía e independencia contenidas en la Convención Interamericana de los Derechos Humanos de las Personas Mayores

Martin Masterman-Lister v Brutton \& Co, A2/2002/0691 \& 0692 EWCA Civ 1889 (The Supreme Court of Judicature Court of appeal (Civil division) 2002). Recuperado de http://bit.ly/2IKfU6e

Massip, J. (2003). Les incapacités. Étude théorique et pratique. París: Defrénois.

Mislawski, R. (2000). Dignité, autonomie, vulnérabilité: approche juridique. En E. Hirscht (Dir.), Traité de bioéthique (Vol. 1, pp. 262-280). Toulouse: Erès.

Moracchini-Zeidenberg, S. (2012). L'acte personnel de la personne vulnérable. RTDciv: Revue trimestrielle de droit civil, (1), 21-32.

Organización de Estados Americanos [OEA]. (2015). Convención interamericana sobre la protección de los derechos humanos de las personas mayores. Recuperado de http://bit.ly/2kh8tDg

Pereira Pérez, J. (2013). Las implicaciones jurídicas de la enfermedad de Alzheimer, con un enfoque desde la autonomía de la voluntad en el contexto jurídico cubano. Revista chilena de derecho y ciencia política, 4(2), 11-42. https://doi.org/10.7770/rchdycp-v4n2-art552

Pretty c. Royaume-Uni, 2346/02 (La Cour européenne des droits de l'homme 2002).Recuperado de http://bit.ly/2ILPktz

Puig de la Bellacasa, R. (1988). Concepciones, paradigmas y evolución de las mentalidades sobre la discapacidad. En I/ seminario sobre discapacidad e información (pp. 6396). Madrid: Real Patronato de prevención y de atención a personas con minusvalía.

Rajmil, A. B., \& Llorens, L. R. (2016). Apuntes acerca del régimen de capacidad de las personas humanas en el Código Civil y Comercial de la República Argentina (Ley 26.994). Revista ius, 9(36), 89-117. https://doi.org/10.35487/rius.v9i36.2015.95

Ribot, T. (1888). Les maladies de la volonté. 5a ed. París: Ancienne Librairie Germer BaIlière et Cie. Recuperado de http://bit.ly/2IKgBfQ

Roman, D. (2008). Vieillesse et droits fondamentaux: I'apport de la construction européenne. Revue de droit sanitaire et social, (2), 267-281.

Ruz Lártiga, G. (2013). El mandato de protección futura. Mirada a una medida propuesta por el derecho civil francés para personas en situación de ser protegidas. En I. Henríquez (Coord.), El mandato. Ensayos doctrinarios y comentarios de jurisprudencia (pp. 5-30). Santiago: Thomson Reuters. 
Salvage-Gerest, P. (2009). Les actes dont la nature implique le consentement strictement personnel du majeur en tutelle (C. civ., art. 458. - L. $n^{\circ}$ 2007-308, 5 mars 2007): une catégorie à revoir d'urgence. Droit de la famille, (3).

Schumacher, B. y Meyer, P-Y. (2015). Démence, autonomie décisionnelle et autonomie de soi. Ethica clinica, (77), 43-50.

Sledziewski, E. (2011). La dignité du sujet vulnérable. Droit de la famille, (2), 37-39.

Trigás-Ferrín, M., Ferreira-González, L. y Meijide-Míguez, H. (2011) .Escalas de valoración funcional en el anciano. Galicia clínica, 72(1), 11-16. Recuperado de http://bit.ly/2mdBvo1

Wolff, J., Boult, C., Boyd, C., \& Anderson, G. F. (2005). Newly reported chronic conditions and onset of functional dependency. Journal of the American geriatrics society, 53(5), 851-855. https://doi.org/10.1111/j.1532-5415.2005.53262.x

Para citar este artículo bajo Norma APA 6a ed.

Ruz Lártiga, G. (2019). El impacto en la legislación civil chilena de la recepción de las nociones de autonomía e independencia contenidas en la Convención Interamericana de los Derechos Humanos de las Personas Mayores. Revista de Derecho (Coquimbo. En línea), 26, e3635, http://doi.org/ 10.22199/issn.0718-9753-2019-0002

DOI

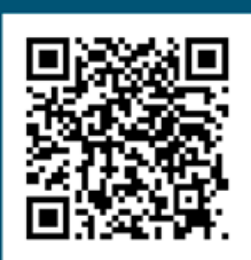

(c) BY

Copyright del articulo: @2019 Gonzalo Ruz

Este es un artículo de acceso abierto, bajo licencia Creative Commons BY 4.0. 